Ecological Applications, 1997, v.7, n.3, pp.1024-1038 ISSN: 1051-0761

doi: 10.1890/1051-0761(1997)007[1024:FYROLB]2.0.CO;2

http://www.esajournals.org/loi/ecap

http://www.esajournals.org/doi/pdf/10.1890/1051-

0761(1997)007\%5B1024\%3AFYROLB\%5D2.0.CO\%3B2

(C) 1997. All rights reserved. Ecological Society of America. 


\title{
FIRST-YEAR RECRUITMENT OF LARGEMOUTH BASS: THE INTERDEPENDENCY OF EARLY LIFE STAGES
}

\author{
Stuart A. Ludsin ${ }^{1}$ And Dennis R. DeVries \\ Department of Fisheries and Allied Aquacultures, Alabama Agricultural Experiment Station, \\ Auburn University, Auburn, Alabama 36849 USA
}

\begin{abstract}
Four early life events (i.e., hatching, the ontogenetic diet shift to piscivory, fall lipid accumulation, and the first winter) are conceptualized as being critical to 1 st-yr recruitment success of largemouth bass (Micropterus salmoides) via cause-and-effect associations among them. Toward this end, we conducted a multiple life-stage investigation of largemouth bass to examine the functional dependency and significance to recruitment of these temporally separated early life events. Specifically, we quantified growth and survival of two largemouth bass year-classes in six Alabama ponds from hatching to the end of the first winter.

The first winter was an important survival bottleneck with lower largemouth bass survival in ponds with smaller largemouth bass (high-density ponds), relative to ponds with larger fish (low-density ponds). While cannibalism was not important, we found sizedependent first-winter mortality to be regulated directly by lipid reserves (i.e., triglycerides) accumulated during fall, and indirectly by both hatch date and the ontogenetic diet shift to piscivory during summer. Early-hatched largemouth bass attained an initial length advantage, remaining large relative to late-hatched fish, despite the relatively higher growth rate of late-hatched fish during their first month of life. Enhanced size permitted earlyhatched fish to become piscivorous before late-hatched fish, increasing their access to fish prey (i.e., sunfishes) during fall. This in turn elevated their fall lipid accumulation and winter survival above that of late-hatched fish. Our results indeed suggest that 1st-yr recruitment of largemouth bass in southern systems is governed by several functionally dependent critical events. Because each is likely vital to understanding recruitment variability, we suggest that future recruitment studies should adopt a more synthetic (i.e., multiple life-stage) approach.
\end{abstract}

Key words: critical period; first-winter mortality; hatch date; Iatroscan; largemouth bass; lipids; Micropterus salmoides; otoliths; prey availability; recruitment; size-dependent survival; triglycerides.

\section{INTRODUCTION}

In highly fecund organisms that provide little parental care (e.g., most plants, invertebrates, and fishes), factors affecting early life stages may be particularly important to understanding recruitment variability because small size and high abundance render these organisms more susceptible to mortality than during later stages (Confer and Cooley 1977, Houde 1989, Schupp 1990). Early in life, biotic interactions can result in density and size-dependent population regulation (Feminella and Resh 1990, Louda et al. 1990, Tonn et al. 1994). In addition, abiotic forces can influence population demographics directly via density-independent mortality (Aiken 1968, Freeberg et al. 1990, Wagner and Spira 1994), or indirectly by mediating biotic interactions (Adams et al. 1982, Adams and DeAngelis

Manuscript received 12 April 1996; revised 14 August 1996; accepted 30 August 1996; final version received 21 October 1996.

${ }^{1}$ Present address: Aquatic Ecology Laboratory and Department of Zoology, The Ohio State University, 1314 Kinnear Road, 227 Research Center, Columbus, Ohio 43212 USA.
1987). The wide array of factors affecting mortality during early life often produces nonuniform population survival, such that brief critical periods of high mortality can exist (sensu Hjort 1914), each with its own unique controlling mechanisms, and each likely vital to determining recruitment to adult stages (Petranka and Sih 1986, Louda et al. 1990). As such, the recruitment process of these organisms can be quite complex.

Despite this apparent complexity, most early life history studies aimed at understanding recruitment variability have taken a restricted approach, only addressing growth and survival during isolated life stages (e.g., Aiken 1968, Isely 1981, Turnock 1993). Aside from overlooking potential critical events operating during other life stages, this approach does not allow evaluation of mechanisms that may link temporally distinct early life events. Considering that growth and survival during any life period is dependent on success during previous periods (Houde 1987), such single life-stage investigations conceivably make understanding and prediction of recruitment variability difficult for many organisms. 
In this study, we use a multiple life-stage approach to determine the interdependency of early life events of young-of-year largemouth bass (Micropterus salmoides) in southern systems, as well as to identify mechanisms influencing recruitment through the first winter of life, after which natural (non-angling) mortality tends to stabilize at low levels (Mraz and Threinen 1957, Green 1982). Specifically, we quantify firstwinter survival of largemouth bass, and assess the relevance of hatch date, the ontogenetic diet shift to piscivory during summer, and fall lipid stores to wintering success. Using these results, we then provide a conceptual model describing 1st-yr survival of largemouth bass that may aid fishery managers in predicting recruitment success.

\section{BACKGROUND}

Because of its economic and ecological significance, a vast amount of research has been devoted to explaining recruitment variability of largemouth bass populations, with recent emphasis focusing primarily on growth and survival during early life stages (e.g., Isely 1981, Miranda and Hubbard 1994a, b, Goodgame and Miranda 1993). Our current conceptual understanding of 1 st-yr recruitment dynamics of largemouth bass stems directly from early life history investigations conducted on this species, as well as other top-level piscivores (Oliver et al. 1979, Henderson et al. 1988, Thompson et al. 1991, Buijse and Houthuijzen 1992), and suggests that four critical early life periods (or events) likely regulate recruitment success: (1) time of hatching (Isely and Noble 1987, Phillips et al. 1995), (2) the ontogenetic diet shift to piscivory (Aggus and Elliot 1975, Shelton et al. 1979), (3) fall lipid accumulation (Sullivan 1986, Miranda and Hubbard 1994a), and (4) the first winter (Isely 1981, Miranda and Hubbard 1994a). Below, we synthesize previous research to outline theoretical relationships among these early life events.

Early-hatched fish are generally larger than latehatched fish at completion of their first growing season, with the larger size of early-hatched fish emanating from both a longer growing period and enhanced prey availability relative to late-hatched fish (Miller and Storck 1984, Maceina and Isely 1986, Trebitz 1991, Phillips et al. 1995). Because fish size and gape are positively correlated (Hambright 1991), larger (i.e., older) largemouth bass would be expected to make the transition from a diet of small, less nutritional prey items (i.e., invertebrates) to one of large, higher quality prey items (i.e., fish) before smaller largemouth bass, thus exacerbating growth disparities (Miller and Storck 1984, Keast and Eadie 1985, Maceina and Isely 1986). Enhanced piscivory by large fish also would presumably allow for greater lipid accumulation during fall relative to small fish (Keast and Eadie 1985, Buijse and Houthuijzen 1992).

Because largemouth bass feeding activity either ceases or is reduced during winter, survival is thought to depend on lipid stores accumulated by fall (Sullivan 1986, Miranda and Hubbard 1994a). Lower mass-specific metabolism of large fish relative to small fish (Shuter and Post 1990), coupled with elevated fall lipid stores of large fish, suggest that survival of large fish should be higher than that of small fish (Oliver et al. 1979, Henderson et al. 1988, Thompson et al. 1991, Miranda and Hubbard 1994a).

Two notable shortcomings exist in this conceptual framework. First, we simply do not understand the significance of the first winter of life to largemouth bass recruitment. Size-dependent winter survival patterns have only been observed in less than one-half of published studies on this predator (Aggus and Elliot 1975, Adams et al. 1982, Boxrucker 1982, Miranda and Hubbard $1994 a, b$ ), with no understanding as to the cause of the inconsistency. Secondly, because previous studies have only focused on one or two life stages, mechanisms blending the suite of critical early life events and linking them to eventual recruitment success are largely theoretical (Gutreuter and Anderson 1985, Adams and DeAngelis 1987, Trebitz 1991). It is these shortcomings that may explain our inability to forecast the relative recruitment success of yearly cohorts of largemouth bass.

\section{Methods \\ Study sites}

We stocked six ponds (2-5 ha; see Boyd and Shelton 1984 for limnological details) in Lee County, Alabama with yearling lepomid sunfish (primarily bluegill [Lepomis macrochirus]; 2500 fish/ha) in winter 19901991 and young-of-year largemouth bass (250 fish/ha) in June 1991. Before stocking, all ponds were drained and remaining puddles treated with rotenone to eliminate remaining fish. Grass carp (Ctenopharyngodon idellus) fingerlings were stocked (12 fish/ha) into each pond to control macrophytes. After monitoring ponds for $1 \mathrm{yr}$ (1992) as largemouth bass-sunfish systems, we added adult gizzard shad (Dorosoma cepedianum) to three ponds in February 1993 (77 fish/ha) to assess the importance of gizzard shad in influencing pond community structure. Gizzard shad, however, only survived to juvenile stages in one pond during 1993 (S. Ludsin and D. DeVries, unpublished data). In addition, none of these young-of-year gizzard shad were available as forage to young-of-year largemouth bass during summer or fall 1993 because of largemouth bass gape limitations (Ludsin 1994). Thus, we will not consider the implications of gizzard shad presence here.

\section{Assessing first-winter survival}

To enable us to identify changes in young-of-year largemouth bass population demographics over winter, we estimated population size within ponds during late fall and early spring (as temperatures approached $10^{\circ} \mathrm{C}$; 
measured hourly via a thermograph at a depth of $1 \mathrm{~m}$ in one pond) of both 1992-1993 and 1993-1994 using a multiple census mark-recapture method (Ricker 1975). During 1-12 December 1992 and 29 November through 10 December 1993, we collected young-ofyear largemouth bass three times in each pond via DC-electrofishing (120 pulses/s; 3-4.5 amps). After we measured (total length [TL], nearest $1 \mathrm{~mm}$; total body mass, to the nearest gram of wet mass) and marked fish, we released them at four to six littoral sites in each pond. We waited 2-4 d between marking events within a pond to ensure dispersal of marked fish. One pond was eliminated during 1992-1993 due to naturally low fall numbers of young-of-year fish, which precluded us from estimating population size.

We marked largemouth bass subcutaneously by injecting a nontoxic acrylic paint into the ventral side of the caudal peduncle (Lotrich and Meredith 1974, Hill and Grossman 1987), leaving an inconspicuous mark. We assigned fish to one of three length classes $(<100$ $\mathrm{mm}, 100-149 \mathrm{~mm}$, and $>149 \mathrm{~mm}$ ), each designated by a unique color. Marks allowed us to quantify differential mortality and growth among fish from length classes during winter. Spring population estimates were conducted similarly, except length classes were designated by different paint colors. We collected largemouth bass for spring censuses during 12-25 February 1993 and 21 February through 1 March 1994. To quantify marking mortality, we caged 160 newly marked fish from all three length classes overnight $\left(8-\mathrm{m}^{3}\right.$ cage; 10-15 fish per cage) during early December 1992.

We used the Chapman variation of the Schnabel method (Ricker 1975) to estimate largemouth bass population size $(N)$

$$
N=\sum\left[\left(C_{t} M_{t}\right) /\left(R_{t}+1\right)\right]
$$

where $C_{t}$ was the total sample caught on day $t, M_{t}$ represented the total number of marked fish on day $\mathrm{t}$ (minus known deaths), and $R_{t}$ was the total number of recaptures on day $t$.

We extrapolated length-frequency distributions from both fall and spring collections to the entire population in a pond, as determined by population censuses. To test for differences in length distributions between fall and spring samples, we used Kolmogorov-Smirnov two-sample asymptotic tests (SAS 1990).

Because predation (i.e., cannibalism) can result in size-selective mortality of young-of-year fishes (Chevalier 1973, Post and Evans 1989a, Miranda and Hubbard $1994 b$ ), we quantified diets of adult $(>260 \mathrm{~mm}$ ) largemouth bass collected during October through March of both winters. We collected adult fish monthly by electrofishing, removed stomach contents with plastic tubing (Van Den Avyle and Roussel 1980), and released the fish. Stomach contents were placed on ice in the field, and kept frozen in the laboratory until analyzed.

\section{Assessing lipid content}

To assess the relationship between lipid content and body size, we quantified lipid stores of fish captured during early December, mid-January, and late February during both 1992-1993 and 1993-1994. Young-of-year largemouth bass were collected from all three length classes (approximately eight fish per length class) via electrofishing, and were then measured (nearest $1 \mathrm{~mm}$ $\mathrm{TL}$; nearest $0.1 \mathrm{~g}$ wet mass) and frozen $\left(-20^{\circ}\right.$ to $-12^{\circ} \mathrm{C}$ ). To ensure minimal moisture loss from exposure to air, we placed fish individually into plastic bags containing water, and then wrapped bags with aluminum foil.

Lipid extraction methods were based on previous studies using a Chromarod-Iatroscan TLC-FID (Thin Layer Chromatography-Flame Ionization Detector) system (Parrish 1987). This technique allowed determination of lipid content for individual fish (in contrast to the previously used approach of pooling fish; e.g., Miranda and Hubbard 1994a) and separation of total lipids into five classes: sterol esters, triglycerides, free fatty acids, sterols, and phospholipids. Because triglycerides (TAG) are an important energy source during periods of stress, whereas the other types are tissue components with slow mobilization rates that likely do not reflect an organism's condition (Fraser 1989, Håkanson 1989a, Sheridan 1994), we only focused on changes in TAG during winter.

Because this technique had been used previously only for studies on invertebrates (Fraser 1989, Arts et al. 1993) and small marine fish (Håkanson 1989a, b, Suthers et al. 1992), we modified extraction and development procedures. After fish were thawed and stomach contents removed, we added deionized water (end-volume $=50-500 \mathrm{~mL}$ ) and homogenized each fish. We then placed a 5-mL sample of homogenate into a large culture tube $(25 \times 150 \mathrm{~mm})$, added 12.5 $\mathrm{mL}$ each of both $\mathrm{MeOH}$ and $\mathrm{CH}_{2} \mathrm{Cl}_{2}$, and cooled the tube to $4^{\circ} \mathrm{C}$. Following cooling, we sonicated samples $(20 \mathrm{~s})$, added $10 \mathrm{~mL}$ of deionized water, and re-cooled them. We then extracted the lipid phase into a small culture tube $(20 \times 150 \mathrm{~mm})$, and finally into a $2-\mathrm{mL}$ vial. Excess solvent was evaporated at $30^{\circ} \mathrm{C}$ using a N-EVAP analytical evaporator (Organomation Associates, Berlin, Massachusetts, USA). After excess solvent evaporated from $2-\mathrm{mL}$ vials, we added $500 \mu \mathrm{L}$ of $\mathrm{CH}_{2} \mathrm{Cl}_{2}$ to each vial, and stored them at $-20^{\circ} \mathrm{C}$. All glassware and laboratory utensils were rinsed with $\mathrm{CH}_{2} \mathrm{Cl}_{2}$ before use.

Samples were prepared for analysis by placing a 1.0$\mu \mathrm{L}$ spot of sample on a desiccated silica-coated quartz rod (Chromarod-SIII; Iatron Laboratories, Tokyo, Japan). After setting samples in a humidity chamber for $10 \mathrm{~min}$, we developed them for $50 \mathrm{~min}$ in a gas chromatography chamber containing a solution of $87: 13$ : 0.05 hexane:ether:acetic acid. Lipids were then quan- 
tified with an Iatroscan MK-5 TLC-FID Analyzer (Iatron Laboratories, Tokyo, Japan).

We ran each sample in duplicate, and cleaned rods after every other run to remove residue. To ensure cleanliness of rods, a randomly chosen blank rod was run simultaneously with samples. Output from the Iatroscan $(\mathrm{mV} / \mathrm{mm})$ was converted to micrograms using regression equations determined from a commercially prepared standard, and values were extrapolated to the entire fish biomass.

\section{Winter diets, fall prey availability, and the transition to piscivory}

To determine winter feeding habits of young-of-year largemouth bass, we quantified stomach contents of fish collected for lipid analyses. Prior to homogenizing fish for lipid analyses, we removed stomach contents (fish with empty stomachs were noted), and preserved them in $95 \% \mathrm{EtOH}$. We identified stomach contents to genus for fish, to family for macroinvertebrates, and to order for zooplankton. Fish and macroinvertebrates were measured to the nearest $1 \mathrm{~mm}$, while zooplankton were measured to the nearest $0.05 \mathrm{~mm}$. We quantified biomass (mg/g wet mass) of ingested prey items using length-weight regressions (fish: Carlander 1977, Werner and Hall 1988; macroinvertebrates: Smock 1980; zooplankton: Pace and Orcutt 1981, Culver et al. 1985). We used a two-way ANOVA $(\alpha=0.05)$ to quantify differences in diet biomass among young-of-year largemouth bass length classes and winter months (December, January, February) for both winters.

To quantify availability of lepomid sunfishes (hereafter referred to as sunfish) as prey to young-of-year largemouth bass, we seined $(4.5 \times 1.0 \mathrm{~m} ; 3-\mathrm{mm}$ mesh $)$ ponds every 2 wk during April through October of both 1992 and 1993. During November through March, ponds were seined once per month. Three sites per pond (5 $\mathrm{m}$ of shoreline per site) were sampled. All seined fish were preserved $(95 \% \mathrm{EtOH})$, counted, and a subsample measured ( $\geq 50$ individuals of each genus, nearest 1-mm TL) in the laboratory. Because largemouth bass are gape-limited predators, prey availability varies with both largemouth bass and prey size. To compare sunfish availability to 1-mm size groups of young-ofyear largemouth bass during mid-November 1992, and July, September, and mid-November 1993, we assumed that only sunfish less than one-third of predator total length could be consumed (Lawrence 1958, Shelton et al. 1979). We estimated prey size distributions and abundances via seining, while young-of-year predator size distributions were obtained through electrofishing surveys.

We qualified stomach contents of young-of-year largemouth bass ( $\approx 45$ per pond) collected on 8-9 July 1993 to quantify the ontogenetic diet shift to piscivory during summer. We identified prey items as either fish (to genus) or invertebrates, and recorded the number of empty stomachs.
Hatch date and summer growth

We examined otolith microstructure to calculate "swimup dates" (generally considered to be at the start of exogenous feeding on zooplankton) and back-calculated individual lengths of young-of-year largemouth bass collected on 8-9 July 1993 via electrofishing ( $N$ $=75-125$ fish per pond). Because daily growth rings from yolk-sac larval stages are not discernable in juvenile fish (Miller and Storck 1982, 1984), we used swimup date as an indicator of hatch date, which typically occurs 5-8 d earlier (Kramer and Smith 1962).

Daily growth micro-increments on otoliths have been validated for largemouth bass up to 151-d old (Miller and Storck 1982); no young-of-year largemouth bass in our study were older than $115 \mathrm{~d}$ when collected in July. After measuring fish (nearest 1-mm TL; nearest 0.1 -g wet mass), extracting stomach contents, and preparing otoliths (as outlined by Miller and Storck 1982), we made three nonconsecutive ring counts on each otolith. If the three counts were within $3 \mathrm{~d}$, we used the highest count. If counts agreed within $10 \%$, we averaged them. If counts differed by $>10 \%$, we made a fourth count. Then, if three of four counts were within $10 \%$, the average of the three was used; otherwise the otolith was discarded (six fish). We calculated swimup dates by subtracting the number of rings from the date of collection.

We initially selected a subsample of 60 fish per pond for otolith analyses such that its length-frequency distribution closely represented the distribution for the entire sample collected in the field. Because subsample selection was not random, extrapolation of swimup dates to the complete sample was necessary. Within each pond, we placed sampled fish into 10 -mm length categories, and then into 7-d swimup intervals within each length group. Swimup date distributions within length groups were then converted into percentages, and extrapolated to the entire sample (Maceina et al. 1995). We calculated daily average growth rate (DGR; $\mathrm{mm} / \mathrm{d}$ ) from the equation

$$
\mathrm{DGR}=\left(\mathrm{TL}_{\mathrm{c}}-6\right) / \mathrm{age}
$$

where $\mathrm{TL}_{c}$ was the total length at capture in July, age was the number of days from swimup (as determined by otolith counts), and $6 \mathrm{~mm}$ was subtracted to correct for length obtained by the time of swimup (Goodgame and Miranda 1993).

We determined back-calculated total length $\left(\mathrm{TL}_{\mathrm{p}}\right.$; $\mathrm{mm}$ ) after each of the first $5 \mathrm{wk}$ following swimup using the direct proportion method (Maceina et al. 1995)

$$
\mathrm{TL}_{\mathrm{p}}=\left[\left(O_{\mathrm{a}} / O_{\mathrm{r}}\right) * \mathrm{TL}_{\mathrm{c}}\right]+6
$$

where $O_{\mathrm{a}}$ was the otolith distance (nearest $0.001 \mathrm{~mm}$ ) from the nucleus to every seventh ring, $O_{\mathrm{r}}$ was the otolith radius (nearest $0.001 \mathrm{~mm}$ ), $\mathrm{TL}_{\mathrm{c}}$ was the total length $(\mathrm{mm})$ of the fish at collection in July, and $6 \mathrm{~mm}$ was added to correct for length obtained by the time of swimup (Goodgame and Miranda 1993). 
Back calculation techniques such as this, which rely on fish-to-otolith size ratios, have recently been criticized for underestimating length-at-age because otolith size may not increase in direct proportion to fish size in populations characterized by very fast- or slowgrowing fish (Campana 1990, Secor and Dean 1992). Because our primary goal was to compare the relative growth of cohorts of young-of-year largemouth bass during the first $5 \mathrm{wk}$ following swimup, we are confident in the use of this technique for such comparison. The biological intercept method (Campana 1990) is another option for determining back-calculated growth. However, a necessary component of this method (otolith size at hatch) remains an unknown for largemouth bass. In addition, this method has been shown to behave similarly to the direct proportion method (Secor and Dean 1992). Thus, despite not knowing the accuracy of our back-calculated total length estimates (to the nearest $1 \mathrm{~mm}$ ), this method allows for a true comparison of relative total lengths between two cohorts, especially given that slopes of the otolith-on-fish size regression did not differ between cohorts (ANCOVA; $\left.F_{1,263}=1.20, P=0.27\right)$ (Campana 1990, Secor and Dean 1992). If a bias did exist in our back calculations, it should have altered measurements from both cohorts equally.

We used a two-way repeated-measures ANOVA to test for differences in back-calculated total lengths among weekly largemouth bass cohorts during the first 5 wk following swimup. Once we determined that changes in fish length as a function of time differed among cohorts within all ponds (two-way ANOVA; significant cohort-by week interaction, all GreenhouseGeisser adjusted $P=0.0001$ ), we compared mean back-calculated length between an early-hatched cohort (arbitrarily defined as fish with swimup dates between 29 March and 11 April) and a late-hatched cohort (arbitrarily defined as fish with swimup dates between 19 April and 2 May) of young-of-year largemouth bass at the completion of each of the first five post-swimup weeks. Because we conducted individual one-way ANOVAs for each post-swimup week, we used a Bonferroni-adjusted $\alpha$-level of $0.01(\alpha=0.05 / 5$, correcting for ANOVAs conducted for each week) to protect against Type-I error. Differences in fish length in July between cohorts were compared using a one-way ANOVA $(\alpha=0.05)$.

To meet conditions of normality, homoscedasticity, and additivity (Zar 1984), data transformations were applied as necessary. All proportional (percentage) data were arcsine square-root transformed, while $\log ($ mean +1$)$ transformations were applied to lipid and sunfish availability data. Other data transformations are noted in the Results section.

\section{RESULTS}

\section{First-winter survival}

Water temperatures fluctuated throughout winter (1 December through 7 March). Mean daily water tem- peratures $( \pm 1 \mathrm{SD})$ during winter were $10.7^{\circ} \pm 2.0^{\circ} \mathrm{C}$ and $9.7^{\circ} \pm 3.0^{\circ} \mathrm{C} 1992-1993$ and 1993-1994, respectively. The minimum water temperature during 1992 1993 was $7.6^{\circ} \mathrm{C}$ with $25 \%$ of the days $(N=24 \mathrm{~d})$ below $10^{\circ} \mathrm{C}$. During winter 1993-1994, water temperature fell to $4.2^{\circ} \mathrm{C}$ with $56 \%$ of the days $(N=54 \mathrm{~d})$ below $10^{\circ} \mathrm{C}$.

Largemouth bass grew little in length during either winter. While conducting spring population estimates, fall marks were recorded to quantify potential fish growth (i.e., change in length of a fish from a smaller to a larger size class). During spring 1993, 191 fish with fall-1992 marks were captured. Of these, only three fish were in a larger length class (all were only $1 \mathrm{~mm}$ longer than the minimum size for that larger size class). During winter 1993-1994, only 1 of 519 fish collected in spring with fall-1993 marks had moved into a larger length class ( $2 \mathrm{~mm}$ into larger size class).

First-winter mortality patterns of young-of-year largemouth bass were consistent in both magnitude and size selectivity. The mean daily mortality rate (deaths $\left.\cdot \mathrm{d}^{-1} \cdot \mathrm{ha}^{-1}\right)$ did not differ between winters $(t$ test, individual pond data; $t=0.08, P=0.94$; pooled mean $\pm 1 \mathrm{SE}=1.1 \pm 0.3, N=11$ pond-years), and resulted in substantial losses of fish during both winters. Population size declines ranged from 0 to $80 \%$ across ponds, with considerable losses of fish $<150 \mathrm{~mm}$ during both winters. The percentage of largemouth bass that died over winter (as determined from population estimates for individual length classes) was greater for small fish $(<100 \mathrm{~mm})$ than for large fish $(>150 \mathrm{~mm})$ (one-way ANOVA, Tukey hsd, $\alpha=0.05$, pooled across ponds and winters; $F_{2,23}=7.97, P=0.002$ ), with medium (100-149 mm) fish intermediate (Fig. 1a). Sizedependent survival trends produced an increase in mean fish length from fall to spring ( $t$ test; $t=4.87$, $P=0.0001$ for winter $1992-1993 ; t=8.26, P=0.0001$ for winter 1993-1994; Fig. 1b, c), and caused largemouth bass length-frequency distributions to change over winter (Kolmogorov-Smirnov two-sample test, all ponds combined; $D=0.18, P=0.0001$ for winter $1992-1993 ; D=0.10, P=0.0001$ for winter $1993-$ 1994), such that larger fish comprised a greater proportion of the population than did smaller fish during spring vs. fall.

Size-dependent survival was likely not influenced by the marking technique, given that only 1 of 160 marked fish died when caged overnight (i.e., short-term mortality was low). Further, Hill and Grossman (1987) quantified long-term survival (20 wk post-marking) of five stream species and found $100 \%$ survival. Differential mark retention times among largemouth bass length classes also did not appear to bias our results. We recovered $38 \%$ of fall-1992 marks during spring 1993 and $26 \%$ of fall-1993 marks during the spring1994 census, and found that mark loss did not differ among length classes (ANCOVA; $F_{2,8}=1.73, P=0.24$ for winter $1992-1993 ; F_{2,10}=1.28, P=0.32$ for winter 1993-1994). Additionally, Lotrich and Meredith 

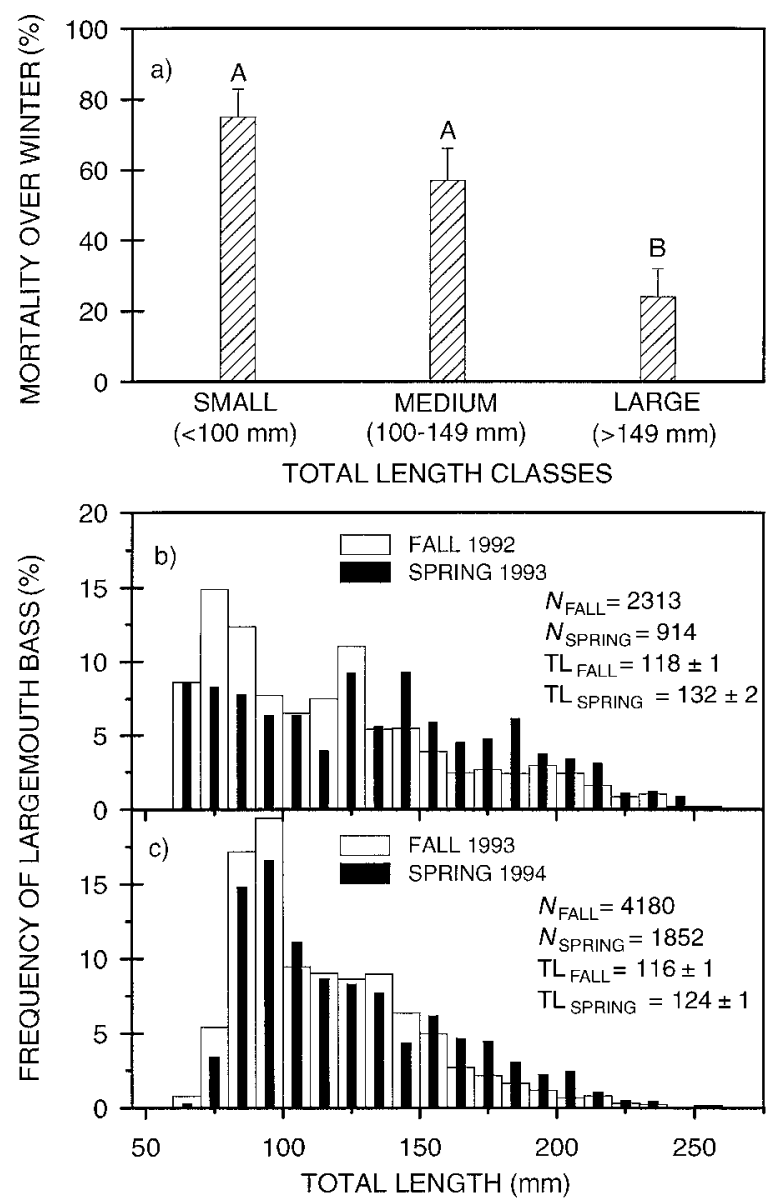

FIG. 1. (a) Mean $(+1 \mathrm{SE})$ percentage first-winter mortality as determined from population estimates of young-ofyear largemouth bass pooled between winters $(N=5$ ponds during 1992-1993; $N=6$ ponds during 1993-1994). Means with the same letter above the bars did not differ (one-way ANOVA, Tukey hsd, $\alpha=0.05)$. $(b+c)$ Fall (open bars) and spring (filled bars) percentage length-frequency distributions for young-of-year largemouth bass collected from ponds in Auburn, Alabama, during (b) 1992-1993 ( $N=5$ pooled ponds; top panel) and (c) 1993-1994 $(N=6$ pooled ponds; bottom panel). Sample size $(N)$ and mean total length $(\mathrm{mm}$ $\pm 1 \mathrm{SE} ; \mathrm{TL})$ are provided for fall and spring.

(1974) observed that similar subcutaneous marks with acrylic paint were discernable for at least 4 mo for several small darter species.

There also was evidence that density-dependent mortality occurred during both winters. The percentage of fish that died over winter within each pond was positively related to fall density (log-transformed data) of young-of-year largemouth bass (correlation, data pooled across both winters, $N=11 ; r=0.80, P=$ 0.003 ). Because young-of-year largemouth bass density during fall (log-transformed data) was positively related to the percentage of small and medium fish within ponds (correlation, data pooled across both winters, $N=11 ; r=0.79, P=0.004)$, density-dependent growth during summer and fall seemingly also occurred.

Finally, winter mortality did not appear to be influenced by cannibalism. Adults fed largely on sunfish and to a lesser extent on invertebrates during winter. Of 125 adult $(>260 \mathrm{~mm})$ largemouth bass stomachs we examined during December 1992 through February 1993, none contained young-of-year largemouth bass $(N=47$ empty). An additional 239 stomachs examined during mid-November 1992 and late March 1993 (i.e., preceding and following the population estimates) only contained two occurrences of cannibalism $(N=110$ empty). During mid-November 1993 through early March 1994, none of the 504 adult largemouth bass stomachs we analyzed contained young-of-year largemouth bass $(N=163$ empty $)$.

\section{Lipid content}

Triglycerides (TAG) were positively related to fish length (Fig. 2a, b). Between 54 and $86 \%$ of the variation in TAG ( $\mathrm{mg} / \mathrm{g}$ wet mass) was explained by largemouth bass length across all months of both winters (regression; all $P=0.0001$ ). Slopes and adjusted means of regression lines for December, January, and February did not differ during winter 1992-1993 (ANCOVA; $F_{2,79}=0.80, P=0.45$ for slopes; $F_{2,81}=0.78, P=$ 0.46 for adjusted means), nor did slopes differ during winter 1993-1994 (ANCOVA; $F_{2,64}=0.78, P=0.46$ ). The adjusted mean of TAG for December 1993, however, was higher than those for January and February 1994 (ANCOVA; $F_{2,66}=9.06, P=0.0003$ ), indicating that TAG diminished during winter (Fig. 2a, b). In addition, points on the $x$-axis of these plots suggest that many small and medium largemouth bass exhausted this energy supply during winter, whereas no large fish (>150 mm) did (Fig. 2a, b).

To further quantify differential lipid losses among largemouth bass length classes, we compared TAG from fish collected during December (pooled across winters) to TAG from largemouth bass collected during January and February (pooled across winters). Pooling of data was justified given that within any length class, there were no interannual differences in TAG during December, January, or February ( $t$ test; all $P \geq 0.12$ ). Similarly, we grouped fish collected during January and February because within any given largemouth bass length class, TAG did not differ between months ( $t$ test; all $P>0.22$ ). TAG (mg/g wet mass) were significantly reduced over winter in both large $(t$ test; $t=3.55, P$ $=0.005, \mathrm{df}=47$; December mean $\pm 1 \mathrm{SE}=12.4 \pm$ 1.6 , January/February mean $\pm 1 \mathrm{SE}=7.0 \pm 1.0)$ and small ( $t$ test; $t=2.17, P=0.04$, df $=53$; December mean $\pm 1 \mathrm{SE}=0.5 \pm 0.2$; January mean $\pm 1 \mathrm{SE}=$ $0.2 \pm 0.1$ ) length classes (Fig. 2c). However, the rate of mobilization of TAG differed among length classes. Nearly $60 \%$ of TAG in small fish were utilized, while large fish only utilized $44 \%$ of this lipid supply. TAG 

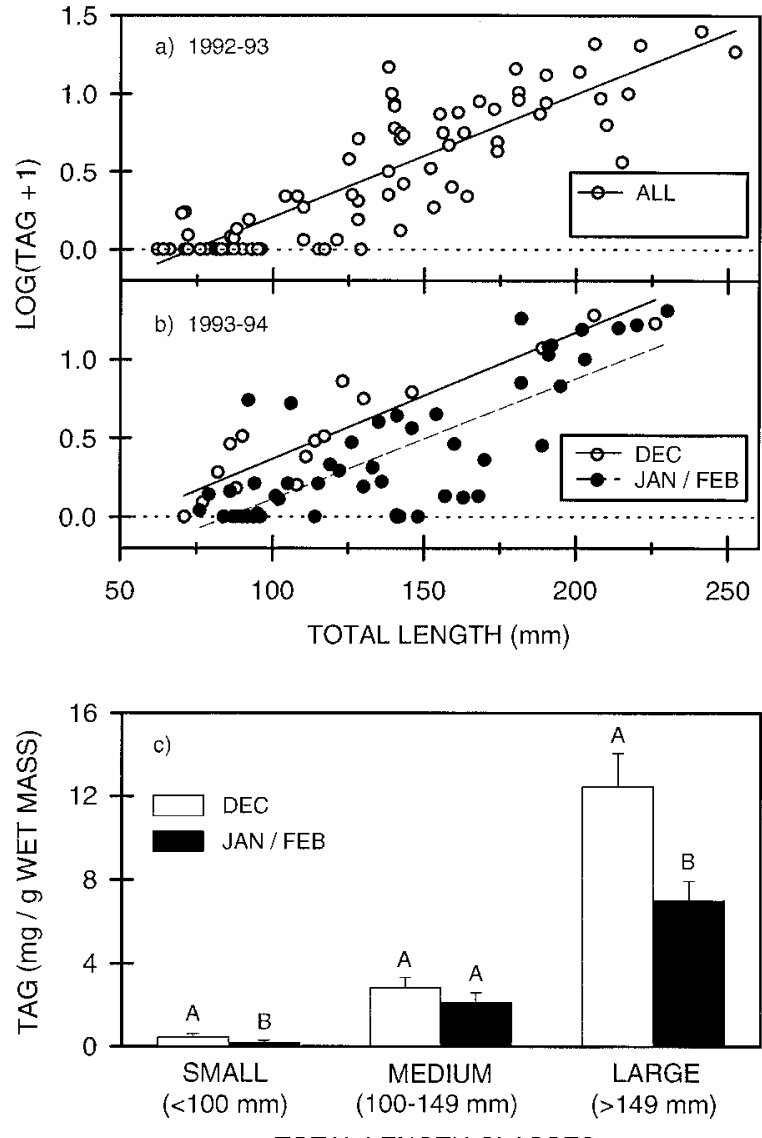

TOTAL LENGTH CLASSES

FIG. 2. Regressions of triglycerides (TAG, mg/g we mass; log-transformed [mean +1$]$ data) on young-of-year largemouth bass length (mm TL) for December, January, and February of winters (a) 1992-1993 (fish were pooled across all months), and (b) 1993-1994 (fish were pooled between January and February). Although samples were pooled across ponds ( $N=5$ during 1992-1993; $N=6$ during 1993-1994), lipid analyses were conducted on individual largemouth bass. (c) Triglycerides (TAG $+1 \mathrm{sE}, \mathrm{mg} / \mathrm{g}$ wet mass) for three length classes of young-of-year largemouth bass during winters 1992-1993 and 1993-1994. Samples were pooled across ponds $(N=5$ ponds during $1992-1993 ; N=6$ ponds during 1993-1994) and between winters. In addition, largemouth bass collected in January and February were pooled. Within a length class, means with the same letter above the bars do not differ (one-way ANOVA, Tukey hsd, $\alpha=0.05$ ).

of medium largemouth bass did not change during winter $(t$ test; $t=1.63, P=0.11$, df $=49)$.

\section{Winter diets, fall prey availability, and transition to piscivory}

A greater percentage of large young-of-year largemouth bass had fish in their diet $(34 \%$, total $N=50)$ than small fish (16\%, total $N=89$ ) ( $Z$ test for binomial data; $Z=2.42, P<0.02$ ) during winter months, with the percentage of piscivorous medium fish $(25 \%$, total $N=59)$ intermediate. Piscivorous largemouth bass were longer $(t$ test; $t=4.21, P=0.0001$; mean TL \pm $1 \mathrm{SE}=152 \pm 8 \mathrm{~mm}$ for piscivorous fish, $N=36$; mean
$\mathrm{TL} \pm 1 \mathrm{SE}=114 \pm 5 \mathrm{~mm}$ for non-piscivorous fish, $N$ $=63)$, and contained more TAG $(t$ test $=3.38, P=$ 0.01 ; mean $\mathrm{TAG} \pm 1 \mathrm{SE}=5.7 \pm 1.0 \mathrm{mg} / \mathrm{g}$ for piscivorous fish, $N=36$; mean TAG $\pm 1 \mathrm{SE}=2.5 \pm 0.1$ $\mathrm{mg} / \mathrm{g}$ for non-piscivorous fish, $N=63$ ) than did nonpiscivorous fish.

Although piscivory was more prevalent in large fish than small ones during winter, total stomach biomass (mg/g wet mass) did not differ among length classes or winter months during winter 1992-1993 (two-way ANOVA, interaction term not included; $F_{2,61}=0.66$, $P=0.56$ for length classes; $F_{2,61}=0.43, P=0.65$ for months) and winter 1993-1994 (two-way ANOVA, interaction term not included; $F_{2,49}=2.88, P=0.07$ for length classes; $F_{2,49}=3.02, P=0.06$ for months). The length class-by-month interaction term also was not significant (two-way ANOVA; $P \geq 0.66$ for both winters). The percentage of empty stomachs ranged from $52-75 \%$ for all length classes of largemouth bass during both winters.

An inspection of data relating sunfish availability during summer and fall to largemouth bass length supported our findings of differential winter diet and lipid content among predator length classes. We found strong positive relationships between the abundance of seined prey available for consumption and largemouth bass size during July (Fig. 3a) and September (Fig. 3b) 1993, confirming that larger young-of-year largemouth bass had access to a greater density of sunfish than did smaller ones. During November of both years, youngof-year predators that were $<100 \mathrm{~mm}$ had essentially no sunfish available to them, whereas all larger fish $(>100 \mathrm{~mm}$ ) had at least some available prey (Fig. 3c, d). Variability in available prey resources to larger predators derived primarily from differing prey population dynamics in ponds during both years (Ludsin 1994). Unfortunately, largemouth bass size distribution estimates from July and September 1992 were not available for similar comparison. Finally, a negative correlation between winter mortality of individual length classes (as determined from population estimates) and sunfish availability during November (as determined from log-transformed sunfish density and largemouth bass gape limitations) (correlation, data pooled between winters; $r=0.4, P=0.046, N=25$ ) reinforces that variation in prey resources during fall likely explains some variation in winter survival.

As would be expected from our estimates of available prey during July 1993, we found that size and diet of young-of-year largemouth bass were strongly related (logistic regression; $\chi^{2}=76.09, P=0.0001$; Fig. 4). Of the fish collected in July 1993, piscivorous fish were longer ( $t$ test; $t=10.38, P=0.0001$; mean TL $\pm \mathrm{SE}$ $=80 \pm 2 \mathrm{~mm}$ for piscivorous fish, $N=84$; mean TL $\pm \mathrm{SE}=57 \pm 1 \mathrm{~mm}$ for non-piscivorous fish, $N=192$ ), and grew more rapidly ( $t$ test; $t=10.61, P=0.0001$; mean daily growth rate $\pm \mathrm{SE}=0.81 \pm 0.02 \mathrm{~mm} / \mathrm{d}$ for piscivorous fish, $N=74$; mean daily growth rate $\pm \mathrm{SE}$ 


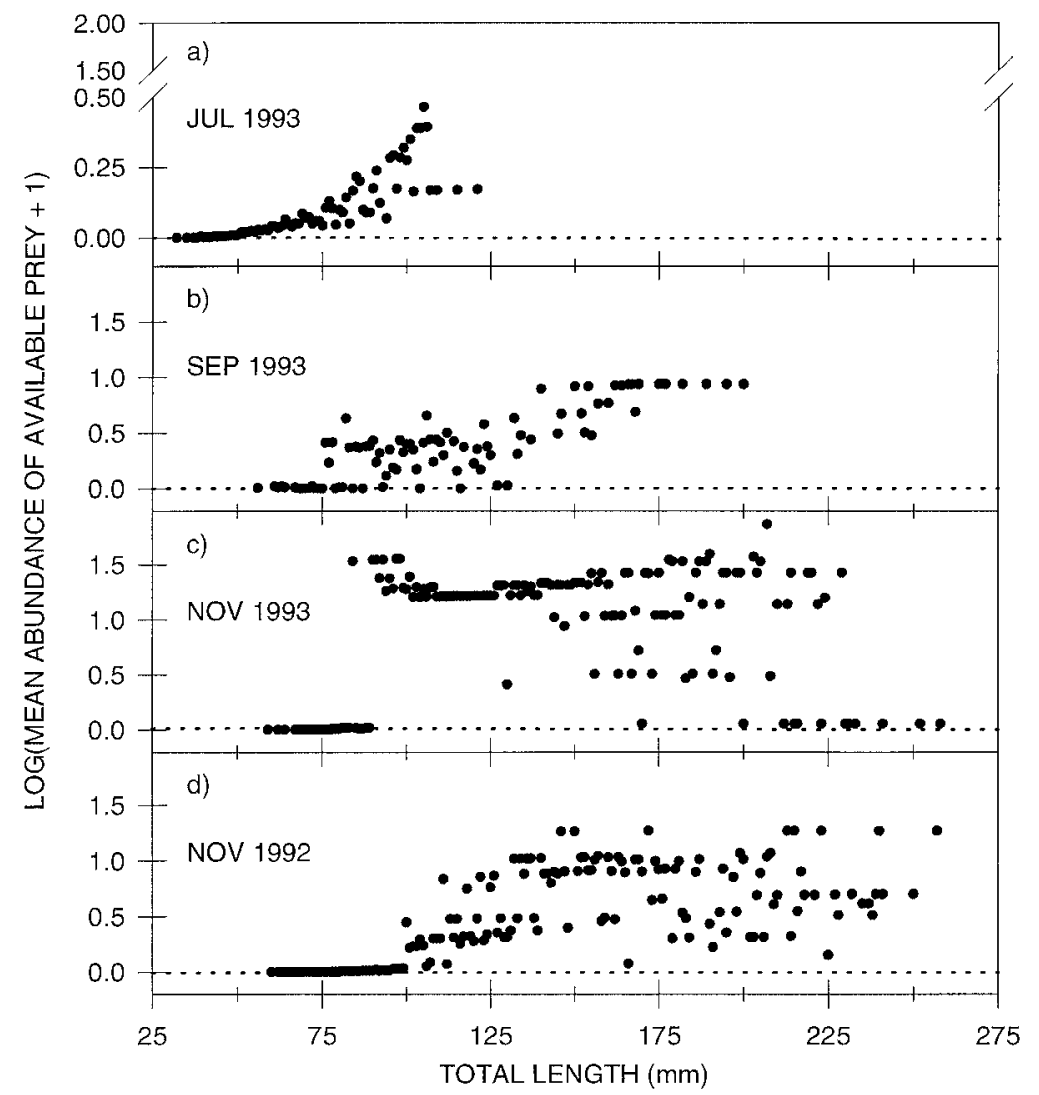

FIG. 3. Log-transformed (mean +1 ) abundance of sunfish available to young-of-year largemouth bass during (a) July 1993, (b) September 1993, (c) November 1993, and (d) November 1992. Prey size distributions and abundances were determined from seine collections ( $N=3$ sites per pond), while predator sizes were determined from electrofishing samples. Only sunfish less than one-third largemouth bass length were considered to be available for consumption. Each point represents the mean abundance of prey available to a predator of that size (1-mm length classes) across ponds $(N=5$ during $1992 ; N$ $=6$ during 1993) in Auburn, Alabama. In order to reduce clutter, error bars were not included.

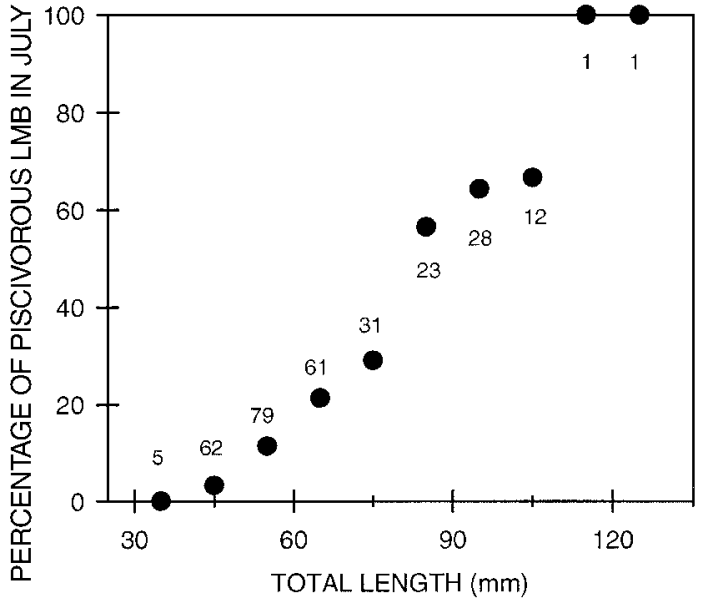

FIG. 4. The percentage of piscivorous young-of-year largemouth bass (LMB) as a function of fish length (within 10-mm length groups) during July 1993. Numbers indicate sample size for each 10 -mm size group.
$=0.59 \pm 0.01 \mathrm{~mm} / \mathrm{d}$ for non-piscivorous fish, $N=$ 177) than their non-piscivorous counterparts. Similarly, a strong, positive relationship existed between the mean percentage of piscivorous young-of-year largemouth bass within a pond during July and the mean total length of those same fish during July (correlation; $r=0.97, P=0.002, N=6$ ), September (correlation; $r=0.86, P=0.03, N=6$ ), and December (correlation; $r=0.92, P=0.01, N=6$ ponds) 1993. Finally, a negative correlation between the mean percentage of young-of-year piscivores in ponds during July 1993 and the percentage of young-of-year mortality within ponds during winter 1993-1994 (correlation; $r=$ $-0.81, P=0.05, N=6$ ) suggests the importance of an early transition to piscivory to recruitment success.

Hatch date and summer growth

Young-of-year largemouth bass collected in July 1993 swam up during 21 March through 14 May at water temperatures between $11.6^{\circ}$ and $25.8^{\circ} \mathrm{C}$. The majority of successful swimup (i.e., those that survived until July), however, occurred while temperatures ranged from $14.6^{\circ}$ to $21.0^{\circ} \mathrm{C}$. The range of swimup 


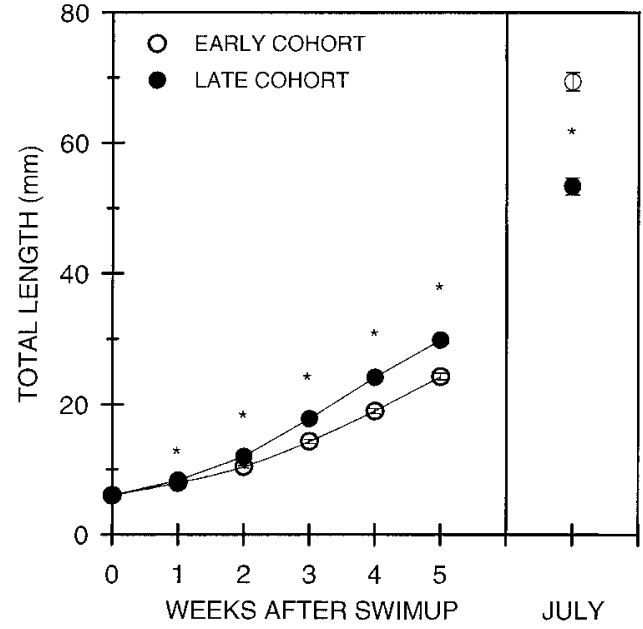

FIG. 5. Comparison of mean back-calculated largemouth bass length ( $\mathrm{mm} \mathrm{TL} \pm 1 \mathrm{SE}$ ) between an early-hatched cohort (arbitrarily defined as fish with swimup dates between 29 March and 11 April) and a late-hatched cohort (arbitrarily defined as fish with swimup dates between 19 April and 2 May) during each of their first five post-swimup weeks ( $N=$ 6 ponds; left panel). The mean length of the early- and latehatched cohorts at time of collection in July are also provided (right panel). Asterisks indicate means that differed between cohorts at a Bonferroni-adjusted $\alpha=0.01$.

dates within ponds varied from 34 to $45 \mathrm{~d}$, with all pond means occurring in early to mid-April. At time of collection in early July, individual fish ranged from 31 to $126 \mathrm{~mm}$.

Young-of-year largemouth bass from the latehatched cohort were always longer during each of their five post-swimup weeks than were fish from the earlyhatched cohort during their five-week post-swimup period (one-way ANOVA, Bonferroni-adjusted $\alpha=0.01$; all $P=0.0001$; Fig. 5, left panel). However, at time of capture in July, fish from the early-hatched cohort were longer than those from the late-hatched cohort (one-way ANOVA; $P=0.0001$; Fig. 5, right panel). Hence, although late-hatched fish grew faster during their post-swimup period than did early-hatched fish, late-hatched fish remained smaller than early-hatched fish during summer. Additionally, because largemouth bass daily growth rate (millimeters per day) during summer 1993 was negatively correlated with mortality over winter during 1993-1994 (correlation; $r=-0.87$, $P=0.02, N=6$ ), summer growth was evidently vital to winter survival.

\section{DISCUSSION}

Mechanisms related to individual size and population density can influence long-term demographics by regulating survival during early life stages (Feminella and Resh 1990, Louda et al. 1990, Tonn et al. 1994). These processes can work independently or jointly, and can influence survival over varying time scales (Houde 1987). For many kinds of poikilotherms and plants, however, survival and overall recruitment success may be controlled by a few critical periods and/or events operating during early life stages (Hjort 1914, Schupp 1990), often causing rapid changes in community structure (e.g., Wicker and Johnson 1987, Sewell and Watson 1993). In this study, we have considered several suggested critical periods for largemouth bass to examine their interdependency and significance to recruitment.

\section{First-winter survival}

In our study, the first winter of life was an important determinant of largemouth bass recruitment success. Quite simply, smaller young-of-year largemouth bass $(<100 \mathrm{~mm})$ did not survive winter as successfully as larger ones, resulting in severe size-dependent and density-dependent mortality. In ponds consisting primarily of individuals in the smallest length class (8 of 11 ponds between both winters), more than one-half of the young-of-year predator population perished during winter. Similar size-dependent first-winter survival patterns have been detected in other southern U.S. largemouth bass populations (Aggus and Elliot 1975, Adams et al. 1982, Boxrucker 1982, Miranda and Hubbard $1994 a, b)$. In Bay Springs Reservoir, Mississippi, sizedependent winter mortality accounted for an $80 \%$ reduction in young-of-year largemouth bass abundance (Miranda and Hubbard 1994a). Likewise, in Bull Shoals Lake, Missouri-Arkansas, Aggus and Elliot (1975) observed complete extirpation of young-of-year fish $<100 \mathrm{~mm}$ during winter with higher survival of large largemouth bass. Given the intensity and acute nature of mortality in this, as well as previous studies, we feel that the first winter constitutes a severe survival bottleneck for young-of-year largemouth bass in southern systems.

Despite its apparent importance to recruitment in southern systems, the first winter of life may not play as vital of a role in more northerly systems - a fact that counters the current conventional wisdom. Because north-temperate systems have shorter growing seasons and longer colder winters than southern systems, it has long been assumed that size-dependent first-winter mortality would increase with increasing latitude (Post and Evans 1989b, Shuter and Post 1990). As such, the relative importance of the first winter as a survival bottleneck should diminish across a north-to-south gradient. However, a review of the published literature suggests otherwise (J. Garvey, personal communication). Studies documenting size-dependent first-winter survival of largemouth bass have all been conducted in southern systems (Aggus and Elliot 1975, Adams et al. 1982, Boxrucker 1982, Miranda and Hubbard 1994 $a, b$, this study), while this phenomenon has yet to be documented in north-temperate areas (Chang 1971, Toneys and Coble 1979, 1980, Isely 1981, Kolander 1992, Kohler et al. 1993, Wright 1993). Although the cause of this discrepancy is not clear, it may be related to the effect on metabolic rate of constantly fluctuating winter 
water temperatures in southern systems. We feel that this important misconception needs to be addressed in future studies, as well as when drawing conclusions from the results of previous work. Clearly, caution must be used when considering the implication of our results for north-temperate systems.

Although adult largemouth bass were not cannibalistic during winter in our study, predation may regulate survival in other systems, or during other seasons (Chevalier 1973, Post and Evans 1989a, Miranda and Hubbard 1994b). Even when daily winter mortality rates are low, the cumulative effects owing to sizedependent cannibalism can increase rapidly, subsequently altering population demographics (Chevalier 1973). Across systems, the degree of cannibalism likely remains a function of fish size (Miranda and Hubbard 1994b, Tonn et al. 1994), availability of shelter (i.e., macrophytes) (Savino and Stein 1982, Miranda and Hubbard 1994b), and abundance of alternate prey (Chevalier 1973, Post and Evans 1989a).

\section{Lipid content}

Lipid content has been suggested to be crucial to winter survival of young-of-year fishes (Oliver et al. 1979, Isley 1981, Henderson et al. 1988, Thompson et al. 1991, Miranda and Hubbard 1994a). Because massspecific metabolism and fall lipid accumulation vary with fish size, first-winter survival of large fish should be greater than that of small fish (Henderson et al. 1988, Thompson et al. 1991, Miranda and Hubbard 1994b). Although the importance of lipids to first-winter survival of largemouth bass has been addressed previously (Isely 1981, Sullivan 1986, Kolander 1992, Miranda and Hubbard 1994a), none of these studies yielded conclusive results. Isely (1981) and Kolander (1992) observed that starved fish used lipids over winter, but did not document size-dependent survival patterns. While Sullivan (1986) showed that winter starvation was related to fall lipid content, the role of largemouth bass size was not discussed. Miranda and Hubbard (1994a) concluded that differential lipid utilization during winter generated size-dependent survival of young-of-year largemouth bass in their study reservoir. However, a follow-up study (Miranda and Hubbard 1994b) suggested that cannibalism also may have played a major role, thereby confounding their overall conclusions.

The relative unimportance of disease (none observed; S. Ludsin, personal observation) and cannibalism in our systems, combined with size-dependent lipid content, suggest that fat stores (i.e., TAG) were essential to survival of young-of-year largemouth bass during winter. Relative levels of TAG were not only greater in larger than in smaller fish at the start of winter, but also constituted a greater percentage of the total lipid of large fish at that time. Additionally, massspecific differences in metabolic rate apparently caused TAG to be utilized more rapidly in small rather than large fish. Because TAG are a short-term energy source that can be mobilized quickly during periods of stress (e.g., starvation, metamorphosis) (Sheridan 1994), as well as a reliable indicator of nutritional states of fish and invertebrates (Fraser 1989, Håkanson 1989a, b), enhanced TAG of large young-of-year largemouth bass conferred a survival advantage to these fish.

\section{Winter diets, fall prey availability, and transition to piscivory}

Differences in foraging habits among length classes also contribute to our understanding of size-dependent survival patterns. Relative stomach content biomass did not differ among predator length classes during winter, implying that small fish were feeding as much as large fish. Why then, do we still see differential depletion of TAG in small vs. large fish? First, small largemouth bass have a higher mass-specific metabolism than large fish. Second, small fish likely spend more time (and energy) searching for prey than large fish because visual acuity and reactive distance increase with increasing fish size (Breck and Gitter 1983, Wahl et al. 1993). Finally, relative to qualitative differences in prey consumption, large largemouth bass exhibited a greater degree of piscivory during early winter than did small largemouth bass. Because fish are of higher caloric value than invertebrates as prey (Keast and Eadie 1985, Hartman and Margraf 1992), large largemouth bass actually ingested more energy per gram prey biomass than did small largemouth bass, despite consuming an equal biomass. In order to maintain the same caloric intake as their larger counterparts, small fish either needed to become piscivorous, which was unlikely, or consume more invertebrate prey, conceivably only furthering energetic losses due to their active foraging behavior (Savino and Stein 1982).

Qualitative differences in prey choice also may aid in understanding the asymmetry between small and large young-of-year largemouth bass in terms of growth and lipid accumulation during the fall. During July 1993, more large than small fish had made the ontogenetic diet shift to piscivory. In addition, as with previous studies (Miller and Storck 1984, Keast and Eadie 1985, Phillips et al. 1995), we found that piscivory led to rapid summer and fall somatic growth. Because gape increases with body size (Hambright 1991), enhanced somatic growth of piscivorous largemouth bass allowed these fish access to a much broader prey assemblage (including fish prey) during summer and fall than small largemouth bass, exacerbating growth differences as well as causing a disparity in terms of fall lipid accumulation. Small predators may have obtained only enough energy from their invertebrate prey to meet the energy demands of their high mass-specific metabolic rate, thereby experiencing reduced growth relative to large fish. Indeed, we found piscivorous largemouth bass were both longer and had amassed a greater supply of TAG than their smaller, non-piscivorous counterparts during late fall and winter. Thus, as previously 
suggested (Shelton et al. 1979, Miller and Storck 1984, Keast and Eadie 1985, Adams and DeAngelis 1987), qualitative differences in summer diet among largemouth bass of varying size could manifest itself in winter survival success.

\section{Hatch date and summer growth}

It has been suggested that recruitment success of young-of-year largemouth bass depends on hatch date, with its potential importance stemming from its control over first-summer growth and the transition to piscivory during summer (Adams and DeAngelis 1987, Trebitz 1991, Phillips et al. 1995). All implications of the importance of hatch date to first-winter survival, however, have remained speculative. Only Kohler et al. (1993) sought to verify the association between hatch date and 1 st-yr recruitment success of largemouth bass empirically. They found no relationship between peak hatch date and juvenile largemouth bass abundance (during the following November or March), nor did they observe size-dependent first-winter mortality within either of their north-temperate study reservoirs.

We, however, found a strong link between hatch date and winter survival. At the conclusion of the first growing season, early-hatched largemouth bass were larger than their late-hatched counterparts. In addition, we found that size differences between cohorts likely controlled the ability to make the ontogenetic diet shift to piscivory because early-hatched largemouth bass expressed a greater degree of piscivory than late-hatched fish in our ponds. The strong associations between piscivory and fall TAG outlined earlier indeed suggest that it is early-hatched fish that are most prone to survive the first winter of life.

We also found, that despite being larger at the conclusion of the first growing season, early-hatched fish actually grew slower during their first weeks following swimup than did late-hatched fish during their postswimup period. These differences likely arose because the late-hatched fish began exogenous feeding at temperatures closer to their growth optimum than did earlyhatched fish (Eipper 1975, Heidinger 1975). Similar results have been shown for larval bloater (Coregonus hoyi) in Lake Michigan, U.S. (Rice et al. 1987) and larval American shad (Alosa sapidissima) (Crecco and Savoy 1985). The initial size advantage, in combination with first access and longer access to all types of prey resources (i.e., zooplankton, macroinvertebrates, fish), afforded by an early hatch date permitted early-hatched fish to remain larger than late-hatched fish at the end of the growing season (Miller and Storck 1984, Goodgame and Miranda 1993, Phillips et al. 1995).

Unfortunately, we have not yet quantified larval mortality among largemouth bass cohorts, limiting our ability to assess the relevance of this life stage as a survival bottleneck. Crecco and Savoy (1985) and Rice et al. (1987) found that initial survival of early-hatched fish was lower than that of late-hatched fish during larval stages. However, of the survivors, there was no indication of which cohorts eventually recruited to the fishery. Although predation and starvation during the transition from endogenous to exogenous feeding can cause considerable mortality in larval marine fishes (Hunter 1981, Houde 1989, 1994), it is unlikely that the larval period serves as a survival bottleneck for freshwater fishes because of their relatively rapid growth rates and large hatch size. Instead, Houde (1994) suggests that survival bottlenecks generated by density-dependent processes aptly operate during juvenile stages for freshwater fishes.

\section{Conceptual model of largemouth bass recruitment}

According to these results, young-of-year largemouth bass recruitment clearly is not determined by growth and survival during any single period, but rather by functionally dependent factors occurring during a number of early life stages. If relationships among life stages are strongly linked, as appears the case in this study, we theoretically can predict how fish would survive during a particular stage given knowledge of growth and survival during previous stages. We suggest that a cohort of fish would typically follow one of two primary sequences of events during the 1 st yr of life, depending on hatch date (Fig. 6). An early-hatched cohort should make the transition to piscivory during late summer, allowing for rapid growth and high lipid (i.e., TAG) accumulation during fall. This would presumably result in high first-winter survival and recruitment to the fishery. Alternatively, a late-hatched cohort would be less prone to make the transition to piscivory, leading to lower accumulation of TAG, and comparatively lower contribution to the new year-class (Fig. 6).

This conceptual model clearly suggests that relative recruitment success of largemouth bass can be predicted due to the strong interdependency and predictive nature of early life events. However, the sequence of events that fish are most likely to follow is best described as a stochastic process, with non-zero transition probabilities between critical events. Thus, whether fish will continue on one or the other path will be described by a probability distribution. In this sense, within each critical period, there exists a non-zero probability that fish can "jump" between the likely pathways (i.e., they can follow the thin arrows on Fig. 6). For instance, this model predicts that late-hatched fish should not make the ontogenetic diet shift to piscivory during summer. We found, however, that $22 \%$ of latehatched fish in our ponds were piscivorous in July. Likewise, we observed that winter survival of small fish $(<100 \mathrm{~mm})$ could be high, (e.g., $57 \%$ during one pond-year). As such, hatch date does not provide an absolute restriction on the degree to which fish contribute to the fishery; factors external to this deterministic sequence of events can intervene.

Given our results in the context of this conceptual 


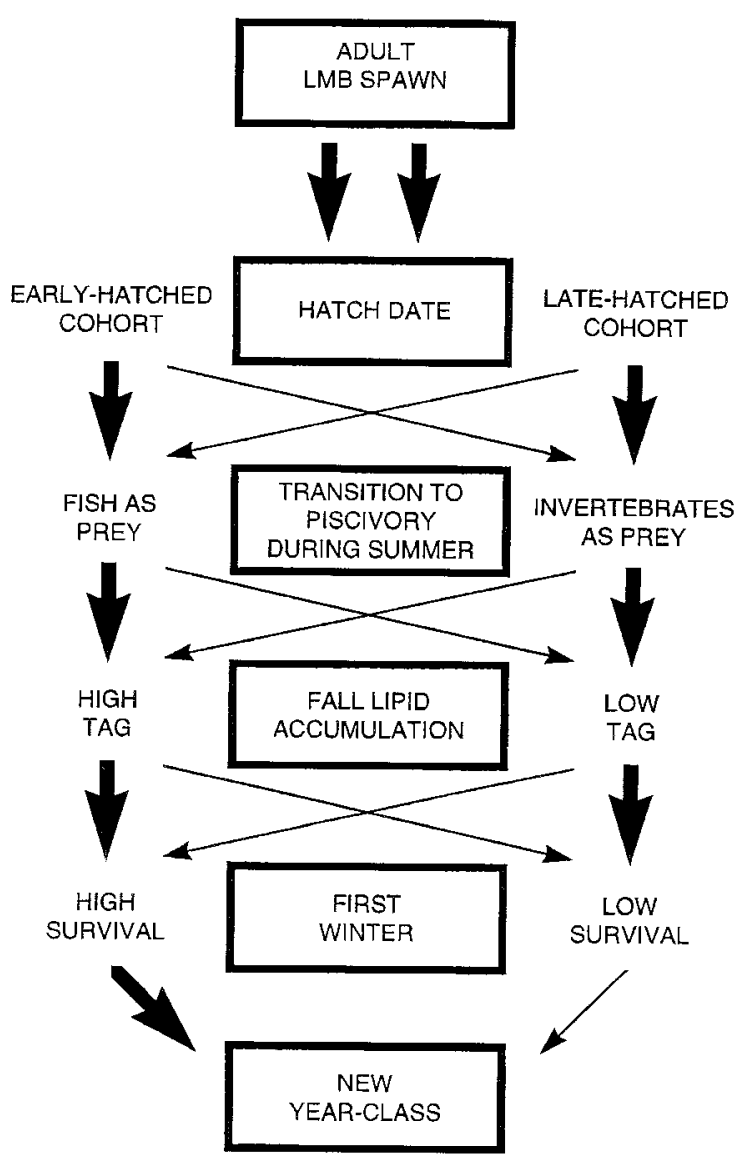

FIG. 6. A conceptual model of factors influencing largemouth bass recruitment during their 1st yr of life in Auburn, Alabama, ponds. Boxes represent periods critical to recruitment, and descriptors beside boxes (e.g., high survival, low survival) represent possible outcomes during each period (excluding death). Bold arrows indicate a high probability of one event leading to another, relative to thin arrows, which indicate a lesser likelihood of that event occurring.

framework, evolutionary-based predictions would suggest continued strong selection for early spawning by largemouth bass in southern systems, increasing the probability of their progeny following the sequence of events outlined on the left side of our model (Fig. 6). Why then do we not always see such selection? One suggestion is that antagonistic agents of selection (bouts of mortality) may occur (Lande and Arnold 1983, Schultz 1993). Because low water temperature and variable winds, typically associated with the early part of the spawning season, can reduce initial growth and survival of progeny from early-spawners relative to late-spawners, selection against early spawning may occur in some years (Kramer and Smith 1962, Crecco and Savoy 1985, Rice et al. 1987). As such, variation in selective pressure across years due to abiotic and biotic influences can yield fit individuals by both earlyand late-spawners (i.e., a stabilizing effect) (Schultz 1993). The contribution of progeny from early- vs. latespawners becomes then a function of the influence of the stochastic nature of abiotic variables on early life history, combined with relatively predictable biotic interactions during the 1 st yr of life.

In addition, the concept of alternating life history strategies (Baylis and Weigmann 1993) may influence the timing of spawning. Using historical data describing population dynamics of a smallmouth bass ( $\mathrm{Mi}$ cropterus dolomieu) population in a Wisconsin, U.S. lake, Baylis and Wiegmann (1993) found that an earlyhatched cohort of smallmouth bass generally grew large enough during its 1 st yr of life to allow it to reproduce during its 2nd yr. Because large smallmouth bass spawn earlier than do small fish (Ridgeway et al. 1991, Wiegmann et al. 1992), and the early-hatched cohort likely reproduced at a smaller body size (i.e., during their 2 nd yr of life) than the remainder of the breeding population, they produced late-hatched fish. Alternatively, a late-hatched cohort generally remained too small to reproduce during its $2 \mathrm{nd} \mathrm{yr}$ of life, and deferred reproduction to the 3rd yr of life (Baylis and Wiegmann 1993). This allowed for enhanced growth of the latehatched cohort before reproduction relative to the early-hatched one, such that the progeny of the latehatched cohort would likely be spawned early. Because of this alternating life history pattern in which old individuals produce offspring that breed at a young age (Baylis and Wiegmann 1993), selection may not systematically operate to favor early-hatched individuals.

\section{CONCLUSiOnS}

Despite their direct application to southern systems, our findings are of significance to all managers needing to make decisions about their fishery. They straightforwardly imply that because of natural stochasticity, we will not be able to accurately predict annual recruitment success, even with knowledge of an organism's early life history. However, these data do begin to provide a basis from which to generate predictions regarding the frequency of successful recruitment. With more studies of this nature (i.e., synthetic, multiplelife stage investigations), managers conceivably could calculate the probability of strong recruitment years, allowing for the formulation of proper long-term harvest strategies, as well as providing a means to keep the public informed such that their expectations match the system's capacity to permit strong recruitment years.

\section{ACKNOWLEDGMENTS}

We thank T. DeVries, A. Foster, J. Hoxmeier, D. Partridge, B. Pine, J. Putman, and B. Shaner for their help in the field and laboratory, and J. Feminella, J. Garvey, C. Howard, E. Irwin, M. Maceina, S. Miranda, J. Rice, R. Stein, R. Wright, and two anonymous reviewers for comments on previous drafts of this manuscript. G. McManus kindly allowed us to use his laboratory and equipment for lipid analyses. We also thank R. Wright, once again, for his programming assistance. This research was supported in part by National Science Foundation grants DEB-9108986 and DEB-9410323, and Federal Aid in Fish Restoration Project F40-R administered 
by the Alabama Game and Fish Division to DRD. This manuscript is publication number 8-965208 of the Alabama Agricultural Experiment Station.

\section{Literature Cited}

Adams, S. M., and D. L. DeAngelis. 1987. Indirect effects of early bass-shad interactions on predator population structure and food web dynamics. Pages 102-117 in W. C. Kerfoot and A. Sih, editors. Predation: direct and indirect impacts on aquatic communities. University Press of New England, Hanover, New Hampshire, USA.

Adams, S. M., R. B. McLean, and M. M. Huffman. 1982. Structuring of a predator population through temperaturemediated effects on prey availability. Canadian Journal of Fisheries and Aquatic Sciences 39:1175-1184.

Aggus, L. R., and G. V. Elliott. 1975. Effects of cover and food on year-class strength of largemouth bass. Pages 317 322 in R. H. Stroud and H. Clepper, editors. Black bass biology and management. Sport Fishing Institute, Washington, D. C., USA.

Aiken, D. E. 1968. The crayfish Orconectes virilis: survival in a region with severe winter conditions. Canadian Journal of Zoology 46:207-211.

Arts, M. T., R. D. Robarts, and M. S. Evans. 1993. Energy reserve lipids of zooplanktonic crustaceans from an oligotrophic saline lake in relation to food resources and temperature. Canadian Journal of Fisheries and Aquatic Sciences 50:2404-2420.

Baylis, J. R., and D. D. Wiegmann. 1993. Alternating life histories of smallmouth bass. Transactions of the American Fisheries Society 122:500-510.

Boxrucker, J. 1982. First year growth and survival of stocked largemouth bass in a small Oklahoma impoundment. Proceedings of the Annual Conference of the Southeastern Association of Fish and Wildlife Agencies 36:369-376.

Boyd, C. E., and J. L. Shelton. 1984. Observations on the hydrology and morphometry of ponds on the Auburn University Fisheries Research Unit. Alabama Agricultural Experiment Station, Auburn, Alabama, USA.

Breck, J. E., and M. J. Gitter. 1983. Effect of fish size on the reactive distance of bluegill (Lepomis macrochirus) sunfish. Canadian Journal of Fisheries and Aquatic Sciences 40:162-167.

Buijse, A. D., and R. P. Houthuijzen. 1992. Piscivory, growth, and size-selective mortality of age 0 pikeperch (Stizostedion lucioperca). Canadian Journal of Fisheries and Aquatic Sciences 49:894-902.

Campana, S. E. 1990. How reliable are growth back-calculations based on otoliths? Canadian Journal of Fisheries and Aquatic Sciences 47:2219-2227.

Carlander, K. D. 1977. Handbook of freshwater fishery biology. Volume 2. The Iowa State University Press, Ames, Iowa, USA.

Chang, K. B. 1971. Population characteristics of largemouth bass and bluegill in a Missouri pond with evaluation of some sampling methods. Thesis. University of Missouri, Columbia, Missouri, USA.

Chevalier, J. R. 1973. Cannibalism as a factor in first year survival of walleye in Oneida Lake. Transactions of the American Fisheries Society 102:739-744.

Confer, J. L., and J. M. Cooley. 1977. Copepod instar survival and predation by zooplankton. Journal of the Fisheries Research Board of Canada 34:703-706.

Crecco, V. A., and T. F. Savoy. 1985. Effects of biotic and abiotic factors on growth and relative survival of young American shad, Alosa sapidissima, in the Connecticut River. Canadian Journal of Fisheries and Aquatic Sciences 42: $1640-1648$.

Culver, D. A., M. M. Boucherle, D. J. Bean, and J. W. Fletcher. 1985. Biomass of freshwater crustacean zooplankton from length-weight regressions. Canadian Journal of Fisheries and Aquatic Sciences 42:1380-1390.

Eipper, A. W. 1975. Environmental influences on the mortality of bass embryos and larvae. Pages $295-305$ in R. H. Stroud and H. Clepper, editors. Black bass biology and management. Sport Fishing Institute, Washington, D.C., USA.

Feminella, J. W., and V. H. Resh. 1990. Hydrologic influences, disturbance, and intraspecific competition in a stream caddisfly population. Ecology 71:2083-2094.

Fraser, A. J. 1989. Triacylglycerol content as a condition index for fish, bivalve, and crustacean larvae. Canadian Journal of Fisheries and Aquatic Sciences 46:1868-1873.

Freeberg, M. H., W. W. Taylor, and R. W. Brown. 1990. Effect of egg and larval survival on year-class strength of Lake Whitefish in Grand Traverse Bay, Lake Michigan. Transactions of the American Fisheries Society 119:92100.

Goodgame, L. S., and L. E. Miranda. 1993. Early growth and survival of age-0 largemouth bass in relation to parental size and swim-up time. Transactions of the American Fisheries Society 122:131-138

Green, D. M. 1982. Population dynamics and management of largemouth bass (Micropterus salmoides) and chain pickerel (Esox niger) in Dryden Lake, New York. Dissertation. Cornell University, Ithaca, New York, USA.

Gutreuter, S. J., and R. O. Anderson. 1985. Importance of body size to the recruitment process in largemouth bass populations. Transactions of the American Fisheries Society 114:317-327.

Håkanson, J. L. 1989a. Analysis of lipid components for determining the condition of anchovy larvae, Engraulis mordax. Marine Biology 102:143-151.

- 1989b. Condition of larval anchovy (Engraulis mordax) in the Southern California Bight, as measured through lipid analysis. Marine Biology 102:153-159.

Hambright, K. D. 1991. Experimental analysis of prey selection by largemouth bass: role of predator mouth width and prey body depth. Transactions of the American Fisheries Society 120:500-508.

Hartman, K. J., and F. J. Margraf. 1992. Effects of prey and predator abundances on prey consumption and growth of walleyes in Western Lake Erie. Transactions of the American Fisheries Society 121:245-260.

Heidinger, R. C. 1975. Life history and biology of the largemouth bass. Pages 11-20 in R. H. Stroud and H. Clepper, editors. Black bass biology and management. Sport Fishing Institute, Washington, D.C., USA.

Henderson, P. A., H. A. Holmes, and R. N. Bamber. 1988. Size-selective overwintering mortality in the sand smelt, Atherina boyeri Risso, and its role in population regulation. Journal of Fish Biology 33:221-233.

Hill, J., and G. D. Grossman. 1987. Effects of subcutaneous marking on stream fishes. Copeia 2:492-495.

Hjort, J. 1914. Fluctuations in the great fisheries of northern Europe viewed in the light of biological research. Rapports et Procès-Verbaux des Réunions Conseil International pour l'Exploration de la Mer 20:1-228.

Houde, E. D. 1987. Fish early life dynamics and recruitment variability. American Fisheries Society Symposium 2:1729.

2. 1989. Subtleties and episodes in the early life of fishes. Fish Biology 35 (Supplement A):29-38.

1994. Differences between marine and freshwater fish larvae: implications for recruitment. International Council of Environmental Studies Journal of Marine Science 51:91-97.

Hunter, J. R. 1981. Feeding ecology and predation of marine fish larvae. Pages 33-77 in R. Lasker, editor. Marine fish 
larvae: morphology, ecology, and relation to fisheries. Washington Sea Grant Program, Seattle, Washington, USA.

Isely, J. J. 1981. Effects of water temperature and energy reserves on overwinter mortality in young-of-the-year largemouth bass (Micropterus salmoides). Thesis. Southern Illinois University, Carbondale, Illinois, USA.

Isely, J. J., and R. L. Noble. 1987. Use of daily otolith rings to interpret development of length distributions of young largemouth bass. Pages 475-481 in R. C. Summerfelt and G. E. Hall, editors. The age and growth of fish. The Iowa State University Press, Ames, Iowa, USA.

Keast, A., and J. M. Eadie. 1985. Growth depensation in year-0 largemouth bass: the influence of diet. Transactions of the American Fisheries Society 114:204-213.

Kohler, C. C., R. J. Sheehan, and J. J. Sweatman. 1993. Largemouth bass hatching success and first-winter survival in two Illinois reservoirs. North American Journal of Fisheries Management 13:125-133.

Kolander, T. D. 1992. Factors limiting overwinter survival of young-of-the-year largemouth bass in South Dakota. Thesis. South Dakota State University, Brookings, South Dakota, USA.

Kramer, R. H., and L. L. Smith. 1962. Formation of year classes in largemouth bass. Transactions of the American Fisheries Society 91:29-41.

Lande, R., and S. J. Arnold. 1983. The measurement of selection on correlated characters. Evolution 37:1210-1226.

Lawrence, J. M. 1958. Estimated sizes of various forage fishes largemouth bass can swallow. Proceedings of the Annual Conference of Southeastern Association of Game and Fish Commissioners 11:220-225.

Lotrich, V. A., and W. H. Meredith. 1974. A technique and the effectiveness of various acrylic colors for subcutaneous marking of fish. Transactions of the American Fisheries Society 1:140-142.

Louda, S. M., M. A. Potvin, and S. K. Collinge. 1990. Predispersal seed predation, postdispersal seed predation and competition in the recruitment of seedlings of a native thistle in Sandhills Prairie. American Midland Naturalist 124 105-113.

Ludsin, S. A. 1994. Understanding first-year survival of a freshwater piscivore: the interdependency of life-history stages. Thesis. Auburn University, Auburn, Alabama, USA

Maceina, M. J., and J. J. Isely. 1986. Factors affecting growth of an initial largemouth bass year class in a new Texas reservoir. Journal of Freshwater Ecology 3:485-492.

Maceina, M. J., S. J. Rider, and S. T. Szedlmayer. 1995 Density, temporal spawning patterns, and growth of age-0 and age-1 largemouth bass (Micropterus salmoides) in vegetated and unvegetated areas of Lake Guntersville, Alabama. Pages 497-511 in D. C. Secor, J. M. Dean, and S. E. Campana, editors. Recent developments in fish otolith research. University of South Carolina Press, Columbia, South Carolina, USA

Miller, S. J., and T. Storck. 1982. Daily growth rings in otoliths of young-of-the-year largemouth bass. Transactions of the American Fisheries Society 111:527-530.

Miller, S. J., and T. Storck. 1984. Temporal spawning distribution of largemouth bass and young-of-year growth, determined from daily otolith rings. Transactions of the American Fisheries Society 113:571-578.

Miranda, L. E., and W. D. Hubbard. 1994a. Length-dependent winter survival and lipid composition of age-0 largemouth bass in Bay Springs Reservoir, Mississippi. Transactions of the American Fisheries Society 123:80-87.

Miranda, L. E., and W. D. Hubbard. 1994b. Winter survival of age-0 largemouth bass relative to size, predators, and shelter. North American Journal of Fisheries Management 14:790-796.

Mraz, D., and C. W. Threinen. 1957. Angler's harvest, growth rate and population estimate of the largemouth bass of Browns lake, Wisconsin. Transactions of the American Fisheries Society 85:241-255.

Oliver, J. D., G. F. Holeton, and K. E. Chua. 1979. Overwinter mortality of fingerling smallmouth bass in relation to size, relative energy stores, and environmental temperature. Transactions of the American Fisheries Society 108: 130-136.

Pace, M. L., and J. D. Orcutt. 1981. The relative importance of protozoans, rotifers, and crustaceans in a freshwater zooplankton community. Limnology and Oceanography 26: 822-830.

Parrish, C. C. 1987. Separation of aquatic lipid classes by Chromarod thin-layer chromatography with measurement by Iatroscan flame ionization detection. Canadian Journal of Fisheries and Aquatic Sciences 44:722-731.

Petranka, J. W., and A. Sih. 1986. Environmental instability, competition, and density-dependent growth and survivorship of a stream-dwelling salamander. Ecology 67:729736.

Phillips, J. M., J. R. Jackson, and R. L. Noble. 1995. Hatching date influence on age-specific diet and growth of age-0 largemouth bass. Transactions of the American Fisheries Society 124:370-379.

Post, J. R., and D. O. Evans. 1989a. Experimental evidence of size-dependent predation mortality in juvenile yellow perch. Canadian Journal of Zoology 67:521-523.

Post, J. R., and D. O. Evans. 1989b. Size-dependent overwinter mortality of young-of-the-year yellow perch (Perca flavescens): laboratory, in situ enclosure, and field experiments. Canadian Journal of Fisheries and Aquatic Sciences 46:1958-1968.

Rice, J. A., L. B. Crowder, and M. E. Holey. 1987. Exploration of mechanisms regulating larval survival in Lake Michigan Bloater: a recruitment analysis based on characteristics of individual larvae. Transactions of the American Fisheries Society 116:703-718.

Ricker, W. E. 1975. Computation and interpretation of biological statistics of fish populations. Information Canada Bulletin 191, Ottawa, Canada.

Ridgeway, M. S., B. J. Shuter, and E. E. Post. 1991. The relative influence of body size and territorial behavior on nesting asynchrony in male smallmouth bass, Micropterus dolomieu (Pisces: Centrarchidae). Journal of Animal Ecology 60:665-681.

SAS. 1990. SAS/STAT User's Guide. Version 6. Fourth edition. Volume 2. SAS Institute, Cary, North Carolina, USA.

Savino, J. F., and R. A. Stein. 1982. Predator-prey interaction between largemouth bass and bluegills as influenced by simulated, submersed vegetation. Transactions of the American Fisheries Society 111:255-266.

Schultz, E. T. 1993. The effect of birth date on fitness of female dwarf perch, Micrometrus minimus (Perciformes: Embiotocidae). Evolution 47:520-539.

Schupp, E. W. 1990. Annual variation in seedfall, postdispersal predation, and recruitment of a neotropical tree. Ecology 71:504-515.

Secor, D. H., and J. M. Dean. 1992. Comparison of otolithbased back-calculation methods to determine individual growth histories of larval striped bass, Morone saxatilis. Canadian Journal of Fisheries and Aquatic Sciences 49: $1439-1454$

Sewell, M. A., and J. C. Watson. 1993. A "source" for asteroid larvae?: recruitment of Pisaster ochraceus, Pycnopodia helianthoides and Dermasterias imbricata in Nootka Sound, British Columbia. Marine Biology 117:387-398. Shelton, W. L., W. D. Davies, T. A. King, and T. J. Timmons. 1979. Variation in the growth of the initial year class of largemouth bass in West Point Reservoir, Alabama and 
Georgia. Transactions of the American Fisheries Society 108: 142-149.

Sheridan, M. A. 1994. Regulation of lipid metabolism in poikilothermic vertebrates. Comparative Biochemistry and Physiology 107B:495-508.

Shuter, B. J., and J. R. Post. 1990. Climate, population viability, and the zoogeography of temperate fishes. Transactions of the American Fisheries Society 119:314-336.

Smock, L. A. 1980. Relationships between body size and biomass of aquatic insects. Freshwater Biology 10:375383.

Sullivan, K. M. 1986. Physiology of feeding and starvation tolerance in overwintering freshwater fishes. Developmental and Environmental Biology of Fishes 7:259-268.

Suthers, I. M., A. Fraser, and K. T. Frank. 1992. Comparison of lipid, otolith and morphometric condition indices of pelagic juvenile cod Gadus morhua from the Canadian Atlantic. Marine Ecology Progress Series 84:31-40.

Thompson, J. M., E. P. Bergersen, C. A. Carlson, and L. R. Kaeding. 1991. Role of size, condition, and lipid content in the overwinter survival of age-0 Colorado squawfish. Transactions of the American Fisheries Society 120:346353.

Toneys, M. L., and D. W. Coble. 1979. Size-related, first winter mortality of freshwater fishes. Transactions of the American Fisheries Society 108:415-419.

Toneys, M. L., and D. W. Coble. 1980. Mortality, hematocrit, osmolality, electrolyte regulation, and fat depletion of young-of-the-year freshwater fishes under simulated winter conditions. Canadian Journal of Fisheries and Aquatic Sciences 37:225-232.

Tonn, W. M., I. J. Holopainen, and C. A. Paszkowski. 1994. Density-dependent effects and the regulation of crucian carp populations in single-species ponds. Ecology 75:824834.
Trebitz, A. S. 1991. Timing of spawning in largemouth bass: implications of an individual-based model. Ecological Modelling 59:203-227.

Turnock, W. J. 1993. Cold-hardiness of Lacanobia atlantica (Lepidoptera: Noctuidae), and a comparison with three other insect species that overwinter in the same habitat. $\mathrm{Ca}$ nadian Journal of Zoology 71:1710-1714.

Van Den Avyle, M. J., and J. E. Roussel. 1980. Evaluation of a simple method for removing food items from live black bass. The Progressive Fish-Culturist 42:222-223.

Wagner, L. K., and T. P. Spira. 1994. Germination, recruitment and survival in the weedy annual Medicago polymorpha in successive wet and dry years. American Midland Naturalist 131:98-108.

Wahl, C. M., E. L. Mills, W. N. McFarland, and J. S. DeGisi. 1993. Ontogenetic changes in prey selection and visual acuity of the yellow perch, Perca flavescens. Canadian Journal of Fisheries and Aquatic Sciences 50:743-749.

Werner, E. E., and D. J. Hall. 1988. Ontogenetic habitat shifts in bluegill: the foraging rate-predation risk trade-off. Ecology 69:1352-1366.

Wicker, A. M., and W. E. Johnson. 1987. Relationships among fat content, condition factor, and first-year survival of Florida largemouth bass. Transactions of the American Fisheries Society 116:264-271.

Wiegmann, D. D., J. R. Baylis, and M. H. Hoff. 1992. Sexual selection and fitness variation in a population of smallmouth bass, Micropterus dolomieu (Pisces: Centrarchidae). Evolution 46:1740-1753.

Wright, R. A. 1993. Size dependence of growth, consumption and survival in juvenile largemouth bass: combining experimental manipulation and individual-based simulation. Dissertation. University of Wisconsin, Madison, Wisconsin, USA.

Zar, J. H. 1984. Biostatistical Analysis. Second edition. Prentice-Hall, Englewood Cliffs, New Jersey, USA. 